\title{
Curbing excess gestational weight gain in primary care: using a point-of-care tool based on behavior change theory
}

This article was published in the following Dove Press journal: International Journal of Women's Health

\author{
Helena Piccinini-Vallis \\ Michael Vallis \\ Department of Family Medicine, \\ Dalhousie University, Halifax, \\ NS, Canada
}

Introduction: Excess gestational weight gain (GWG) is a risk factor for several adverse outcomes for mothers and their offspring. In Nova Scotia, Canada, approximately $60 \%$ of women experience excess GWG. Outside the pregnancy arena, a patient-centered approach has been shown to promote increased patient adherence to clinician recommendations, and increased intentions for, and attempts at, behavior change. The 5As of Healthy Pregnancy Weight Gain is a tool that assists clinicians to have patient-centered discussions about GWG. This feasibility trial examined the association between training in the use of this tool and women's self-efficacy to manage GWG, readiness to adhere to GWG guidelines, perception of their clinicians' patientcenteredness when discussing GWG, and guideline concordance of total GWG.

Method: Participants were 11 family physicians who provide prenatal care and 24 of their patients who were pregnant. Physicians were randomly assigned to a single 60 -minute training session in the use of the tool or usual care. Consenting patients completed measures of social support, stress, patient-perceived patient-centeredness, self-efficacy, and motivation. At the end of each woman's pregnancy, data pertaining to guideline concordance of GWG were collected.

Results: Comparison of patient participants with prenatal care providers in the trained and untrained groups showed no significant difference in patient-perceived physician patientcenteredness when discussing GWG, self-efficacy to manage GWG, readiness to adhere to GWG guidelines, or GWG congruence with the guidelines.

Conclusion: This feasibility study required very little time commitment and entailed minimal disruption to clinicians' practices. Nonetheless, it was very difficult to recruit clinicians for the study. Although recent theory-driven work showed that prenatal care providers have, overall, high perceived self-efficacy in discussing GWG with their patients, most studies have demonstrated that these providers do not often discuss GWG with their patients; so, there is clearly a mismatch in their perceived self-efficacy and what actually transpires.

Keywords: weight gain in pregnancy, prenatal care providers, patient-centeredness, counseling

\section{Introduction}

Excess weight gain in pregnancy is a risk factor for a number of short- and long-term adverse outcomes for mothers and their offspring. ${ }^{1-3}$ Between 2005 and 2014, approximately $60 \%$ of women delivering at term in Nova Scotia, Canada, gained weight in excess of the Institute of Medicine (IOM) guidelines. ${ }^{4,5}$ These guidelines $^{6}$ are based on prepregnancy body mass index (BMI) categories and include weekly recommendations for gestational weight gain $(\mathrm{GWG}) .{ }^{6-8}$ A number of factors influence guideline concordance of GWG, including unhealthy lifestyle behaviors, lack of clinician or patient knowledge about how much weight should be gained,,$^{9,10}$ maternal age, parity,
Correspondence: Helena Piccinini-Vallis Department of Family Medicine,

Dalhousie University, 6960 Mumford

Road, Suite 0265, Halifax, NS,

B3L 4PI, Canada

Tel + I 9024734700

Fax + I 9024738548

Email helena.piccinini@dal.ca 
prepregnancy BMI, smoking, income, and education. ${ }^{11,12}$ A clinician's advice also potentially influences $\mathrm{GWG},{ }^{13,14}$ although this has not been a consistent finding. ${ }^{15-17}$ One common limitation of existing studies is that "advice" is not operationalized and may refer simply to the clinician addressing the patient in a prescriptive manner. While this cliniciancentered approach might increase patient knowledge, it does not necessarily translate into patient behavior change. ${ }^{18}$ In contrast, a patient-centered approach incorporating motivational and behavior change strategies promotes increased patient acceptance of and adherence to recommendations, as well as increased intentions for, and attempts at, behavior change. ${ }^{19-21}$ This approach involves the clinician striving to understand the whole person, explore the patient's illness experience, find common ground, and cultivate the clinicianpatient relationship in order to address the barriers to initiating and sustaining behavior change. ${ }^{22,23} \mathrm{~A}$ patient-centered approach has been shown to improve patient outcomes and decrease costs to the health-care system. ${ }^{24-26}$ In one recent meta-analysis, physician patient-centeredness increased the odds of adherence by $2.16 .{ }^{27}$ Patient-centeredness can be operationalized and is measurable from a clinician, observer, or patient perspective, ${ }^{28,29}$ the latter being most significantly associated with improved health outcomes. ${ }^{30,31}$

Patients want their primary care physicians to address weight-related issues. ${ }^{32}$ Although the unique relationship these clinicians have with their patients should be facilitative, such discussions occur infrequently. ${ }^{33,34}$ Clinicians perceive several barriers to discussing weight-related matters, including a threat to the patient-clinician relationship, and perceived lack of competence, time, and remuneration. ${ }^{35-38}$ Training in behavior change counseling potentially addresses some of these perceived barriers ${ }^{39-41}$ and improves patients' health behaviors and health outcomes. ${ }^{42,43}$ However, no research has been published on training providers to counsel on pregnancy-related weight gain specifically - a recent systematic review in this area did not identify a single trial. ${ }^{44}$ Evidence outside of the GWG arena suggests that clinicians trained in behavior change counseling struggle to use these skills due to the demanding nature of such counseling from a time management point of view as well as perceived complexity. ${ }^{45}$

Point-of-care tools provide less intensive alternatives to behavior change counseling and may address issues associated with lack of skill and confidence. ${ }^{46}$ An example of a point-of-care tool is the 5As of Obesity Management. ${ }^{23}$ This tool, based on principles of behavior change science and patient-centeredness, assists clinicians to engage in conversations about weight-related behavior change with their patients in a systematic manner that incorporates the patient context. ${ }^{47}$ Pilot data on the use of this tool have shown a twofold increase in the initiation of weight-related discussions between healthcare providers and their patients. ${ }^{48}$ Our team was instrumental in the development, dissemination, and initial evaluation of this tool, and Dr Piccinini-Vallis led a national multidisciplinary endeavor to adapt it to pregnancy, which resulted in the 5As of Healthy Pregnancy Weight Gain tool (5As HPWG). ${ }^{49}$

We are part of a national Canadian research group exploring the potential use of the $5 \mathrm{As}$ HPWG in prenatal care. The aim of the current proof-of-concept study ${ }^{50}$ was to collect data about training in the use of the 5As HPWG in Halifax, NS, Canada.

\section{Research questions}

1. How does training family physicians in the use of the 5As HPWG compare to usual care in terms of:

a. women's perception of their family physicians' patient-centeredness when discussing GWG;

b. women's perceived self-efficacy to manage GWG;

c. women's readiness to adhere to GWG guidelines;

d. the guideline concordance of women's total GWG?

\section{Method}

This study was a pragmatic randomized feasibility trial. Ethics approval was obtained from the Capital District Health Authority Research Ethics Board in Halifax, NS, Canada (file number CDHA-RS/2OI5-277). The trial was registered at ClinicalTrials.gov (registration number NCT02174809).

\section{Participants and setting}

All participants provided written informed consent. Participants were family physicians in Halifax, NS, Canada, who provide prenatal care, and their patients at least 18 years of age who were able to speak English, had a singleton pregnancy, and a normal 18-week ultrasound. In Halifax, most women with uncomplicated, low-risk pregnancies as just described receive prenatal care in a primary care setting, typically by family physicians.

\section{Participant enrolment}

Physicians in Halifax were recruited primarily by personal contact by the investigators, as well as through fax and email. Although recruitment of physicians for research is notoriously difficult, we believed that the fact that the investigators were known to the small "network" of physicians 
who provide prenatal care within the target region would increase the chances of successful recruitment to as high as $50 \%-70 \% .^{51,52}$ Consenting physicians were randomly assigned to training in the use of the 5As HPWG (trained group) or usual care (untrained group). The limited population of potential physician participants necessitated this study to be considered a proof-of-concept study in a defined population. As there was some chance of cross-contamination, those in the trained group were instructed not to discuss the 5As HPWG with other physicians.

Consenting physicians were randomized to the trained or untrained group on the basis of a random number generator. The trained group obtained a single 60-minute in-person training session in the use of the tool. They were shown four videos demonstrating the use of the 5As HPWG with progressively more challenging patients. In addition, they received a paper copy of the 5As HPWG and a desktop dodecahedron illustrating the 5As HPWG. While the training was brief, it was based on a comprehensive training program developed by the Behavior Change Institute at the Nova Scotia Health Authority, described elsewhere. ${ }^{53}$ Physicians in the untrained group received no intervention. All physicians identified potential patient participants (at least 18 years old, ability to speak English, singleton pregnancy) on receipt of a normal routine18-20 week ultrasound report and advised these women of the study at their next prenatal appointment.

\section{Data collection}

Upon enrolment, consenting patients completed a brief questionnaire on demographic items: age, parity, smoking, height, and prepregnancy weight. ${ }^{54}$ The height $(\mathrm{m})$ and prepregnancy weight $(\mathrm{kg})$ measures were used to calculate prepregnancy BMI $\left(\mathrm{kg} / \mathrm{m}^{2}\right)$, which were then categorized by range as follows: $<18.5,18.5$ to $<25.0,25.0$ to $<30.0, \geq 30.0$. Participants also completed measures of social support (ENRICHD Social Support Instrument), ${ }^{55}$ stress (Perceived Stress Scale) ${ }^{56}$ patient-perceived patient-centeredness (a version of the 14-item validated Patient-Perceived Patient-Centeredness Questionnaire $^{29}$ adapted for discussions about GWG), and two behavior change constructs: self-efficacy (General Self-Efficacy Scale, ${ }^{57}$ modified for the context of GWG), and motivation (ie, readiness to adhere to GWG guidelines, using the BCI Traffic Light Assessment, ${ }^{58}$ a validated scale developed by our team). The latter measurement categorized participants' readiness into "ready", "ambivalent", and "not ready".

At the end of each participant's pregnancy, data pertaining to the outcome variable (GWG concordance with the guidelines) were collected. Both the last measured weight during pregnancy and the corresponding gestational week were extracted from each patient's prenatal record after delivery. GWG concordance with the 2009 IOM guidelines ${ }^{6}$ was determined by comparing the total GWG to the guideline recommendations by prepregnancy BMI category. Data were entered into an electronic form and analyzed using SPSS 24.

\section{Results Sample}

Fifteen family physicians were approached and eleven consented to participate in the study (73\%), and five of these physicians were randomized to receive training in the use of the 5As HPWG. A total of 26 patient participants were enrolled, with an average of 3 participants per physician. Of these participants, $11(42.3 \%)$ had physicians who were in the trained group.

One participant developed gestational diabetes and one was lost to follow up. These two participants were therefore not included in any further analyses and the total sample was reduced to 24 participants, including 10 participants (41.7\%) with physicians in the trained group.

\section{Patient characteristics}

The mean age of participants was 32.4 years (SD 3.1, range 28-40) and the mean prepregnancy BMI was 25.0 (SD 3.5, range $19.7-36.3) ; 70.8 \%$ were nulliparous, $16.7 \%$ were primiparous, and $12.5 \%$ were multiparous; $54.2 \%$ had a prepregnancy BMI that fell in the 18.5 to $<25.0$ range, $37.5 \%$ had a prepregnancy BMI that fell in the 25.0 to $<30.0$ range, and $8.3 \%$ had a prepregnancy BMI $>30.0$; the majority of participants (91.7\%) did not smoke. These women all had family physicians in an urban community; however, no variables pertaining to socioeconomic status (SES) were collected.

On a scale of 14 (lowest stress) to 70 (highest stress), the mean perceived stress of women was 33.1 (SD 9.7, range 20-51). The mean perceived social support, on a scale of 7 (lowest support) to 35 (highest support), was 27.3 (SD 3.6, range 19-34).

The mean patient-perceived patient-centeredness when discussing GWG, on a scale of 1 (lowest patient-centeredness) to 4 (highest patient-centeredness), was 2.53 (SD 0.47, range 1.86-3.43). The mean perceived self-efficacy to manage GWG among participants, on a scale of 10 (lowest selfefficacy) to 40 (highest self-efficacy), was 30.2 (SD 4.7, range 18-37). Approximately half of the participants (54.2\%) rated 
Table I Comparison of baseline data between participants with physicians in experimental and control groups

\begin{tabular}{|c|c|c|c|c|}
\hline Variable & Experimental group & Control group & Statistic & $P$-value \\
\hline Age: mean (SD) & $32.80(4.13)$ & $32.07(2.20)$ & $\begin{array}{l}\text { Mann-Whitney } \\
U=66.500\end{array}$ & 0.836 \\
\hline Prepregnancy BMI: mean (SD) & $23.99(2.91)$ & $25.76(3.83)$ & $\begin{array}{l}\text { Mann-Whitney } \\
U=55.000\end{array}$ & 0.380 \\
\hline Stress level: mean (SD) & $33.40(11.17)$ & $32.86(8.97)$ & $t=-0.127$ & 0.900 \\
\hline Perceived social support: mean (SD) & $25.30(3.02)$ & $28.71(3.36)$ & $t=2.556$ & 0.018 \\
\hline $\begin{array}{l}\text { Parity: } \mathrm{n}(\%) \\
0 \\
1 \\
2\end{array}$ & $\begin{array}{l}5(50.0) \\
3(30.0) \\
2(20.0)\end{array}$ & $\begin{array}{l}12(85.7) \\
\mathrm{I}(7.1) \\
\mathrm{I}(7 . \mathrm{I})\end{array}$ & $\chi^{2}=3.650(2)$ & 0.161 \\
\hline $\begin{array}{l}\text { Prepregnancy BMl category: } \mathrm{n}(\%) \\
\quad 18.5 \text { to }<25.0 \\
25.0 \text { to }<30.0 \\
\geq 30.0\end{array}$ & $\begin{array}{l}5(50.0) \\
5(50.0) \\
0(0.0)\end{array}$ & $\begin{array}{l}8(57.1) \\
4(28.6) \\
2(14.3)\end{array}$ & $\chi^{2}=2.198(2)$ & 0.333 \\
\hline $\begin{array}{l}\text { Smoking: } n(\%) \\
\text { No } \\
\text { Yes }\end{array}$ & $\begin{array}{l}9(90.0) \\
I(10.0)\end{array}$ & $\begin{array}{l}13(92.9) \\
\mathrm{I}(7.1)\end{array}$ & $\chi^{2}=0.062(1)$ & 0.803 \\
\hline
\end{tabular}

Abbreviation: BMI, body mass index.

their readiness to adhere to GWG guidelines as "ambivalent", $41.7 \%$ were "ready", and $4.2 \%$ were "not ready".

There was a significant correlation between perceived stress and perceived social support $(r=-0.463, P=0.023$ ), and between perceived stress and perceived self-efficacy to manage GWG ( $r=-0.703, P=0.000)$. There was a significant correlation between perceived social support and perceived self-efficacy to manage $\mathrm{GWG}(r=0.593, P=0.002)$. ANOVA showed no significant relationship between readiness to adhere to GWG guidelines and perceived social support, perceived stress level, perceived self-efficacy to manage GWG, and patient-perceived patient-centeredness when discussing GWG.

All women delivered at term ( $\geq 37$ weeks' gestation), with over half delivering at 40 weeks' gestation. The mean GWG was $14.9 \mathrm{~kg}$ (SD 4.4, range 6.7-25.5). One participant gained insufficient weight, one-third of the sample (33.3\%) had guideline-congruent GWG, and slightly less than twothirds of the sample (62.5\%) experienced excess GWG.

Baseline variables were examined for normality (kurtosis and skewness), and nonnormally distributed variables were analyzed using nonparametric analyses (Mann-Whitney tests). Mean age, prepregnancy BMI, and measures of perceived stress and perceived social support were compared between the participants of trained and untrained physicians; chi-square analysis was used to compare these participants' parity, prepregnancy BMI category, and smoking (Table 1).

There was a significant difference in perceived social support between the groups, with participants whose physicians were in the trained group rating their perceived social support as being lower than those with physicians who were in the untrained group.

\section{Impact of physician training}

As shown in Table 2, comparison of patients in the trained and untrained groups showed no significant difference in mean patient-perceived patient-centeredness when discussing GWG and no significant difference in their mean perceived self-efficacy to manage GWG. Similarly, there was no significant relationship between physician training and readiness to adhere to GWG guidelines or women's GWG congruence with the guidelines.

\section{Predictors/correlates of GWG concordance with the guidelines}

As shown in Table 3, women with GWG that was concordant with the 2009 IOM guidelines ${ }^{6}$ had significantly higher perceived self-efficacy to manage GWG and reported significantly lower perceived stress compared with women who experienced guideline-discordant GWG. However, they did not rate their physicians' patient-centeredness when discussing GWG or their readiness to manage GWG as significantly different.

\section{Discussion}

The main purpose of this feasibility study was to evaluate how incorporating a minimal intervention approach for behavior change counseling, the 5As HPWG, could increase the likelihood of guideline-concordant GWG. However, the study 
Table 2 Impact of physician training on patient outcomes

\begin{tabular}{|c|c|c|c|c|}
\hline Patient outcome & $\begin{array}{l}\text { Patients in } \\
\text { experimental } \\
\text { group }(n=10)\end{array}$ & $\begin{array}{l}\text { Patients in } \\
\text { control group } \\
(n=14)\end{array}$ & Statistic & $P$-value \\
\hline Patient-perceived patient-centeredness: mean (SD) & $2.55(0.45)$ & $2.5 I(0.5 I)$ & $t=-0.188$ & 0.852 \\
\hline Perceived self-efficacy to manage GWG & $28.80(4.64)$ & $31.14(4.6 I)$ & $t=1.225$ & 0.233 \\
\hline $\begin{array}{l}\text { Readiness to adhere to GWG guidelines: } \mathrm{n}(\%) \\
\qquad \begin{array}{l}\mathrm{I}=\text { not ready } \\
2=\text { ambivalent } \\
3=\text { ready }\end{array}\end{array}$ & $\begin{array}{l}\text { I (10) } \\
4(40) \\
5(50)\end{array}$ & $\begin{array}{l}0(0) \\
9(64.3) \\
5(35.7) \\
\end{array}$ & $\chi^{2}=2.321$ & 0.313 \\
\hline $\begin{array}{l}\text { GWG concordance with the guidelines: } \mathrm{n}(\%) \\
\text { Below } \\
\text { Within } \\
\text { Above }\end{array}$ & $\begin{array}{l}0(0) \\
2(20) \\
8(80)\end{array}$ & $\begin{array}{l}\text { I }(7.1) \\
6(42.9) \\
7(50)\end{array}$ & $\chi^{2}=2.469$ & 0.291 \\
\hline
\end{tabular}

Notes: The ranges for the scores are explained in the "Patient characteristics" section. For patient-perceived patient-centeredness the range is I-4. For perceived selfefficacy, the range is $10-40$.

Abbreviation: GWG, gestational weight gain.

was underpowered and we were unable to demonstrate any difference in patient outcomes with the brief training that was undertaken in this study. Specifically, training in the use of the 5As HPWG did not result in an increase in patient-perceived patient-centeredness when discussing GWG, patient perceived self-efficacy to manage GWG, readiness to adhere to GWG guidelines, or GWG congruence with the guidelines. However, patients in the trained group had significantly lower perceived social support than patients in the untrained group, which could have affected their self-efficacy to manage GWG, as there was a significant positive correlation between these two variables. A post-hoc analysis was therefore undertaken comparing patients in the trained and untrained groups on selfefficacy to manage GWG and controlling for perceived social support. The results showed no difference in self-efficacy to manage GWG between the two groups.

Women who experienced guideline-concordant GWG reported significantly higher perceived self-efficacy to manage GWG and significantly lower perceived stress than women who gained excess weight. However, post-hoc analysis comparing guideline concordance and covarying for pre-pregnancy BMI found that women with guidelineconcordant GWG had higher perceived self-efficacy to manage GWG (6.283; $P=0.02)$. Comparison of guideline concordance, covarying for prepregnancy BMI, found that women with guideline-concordant GWG experienced lower perceived stress $(f=4.675, P=0.042)$. Therefore, it appears that self-efficacy enhancement and stress management may play a role in facilitating guideline concordance of weight gain during pregnancy. These results would justify a trial intervention evaluating psychological interventions that would promote these constructs.

One significant threat to the internal validity of this study is the issue of fidelity and competency on the use of the $5 \mathrm{As}$ HPWG. Our experience of delivering the training was that physician participants were not highly engaged in the implementation aspect of the tool. Training sessions were often scheduled late in the day and providers presented as distracted and were not receptive to in session role-plays in the use of the tool. Most providers stated that they were comfortable in using such tools. Lack of effective training compromises the integrity of the intervention. Campbell et al commented on

Table 3 Predictors and correlates of GWG concordance with the guidelines

\begin{tabular}{|c|c|c|c|c|c|}
\hline Variable & $\begin{array}{l}\text { GWG below } \\
\text { guidelines }\end{array}$ & $\begin{array}{l}\text { GWG within } \\
\text { guidelines }\end{array}$ & $\begin{array}{l}\text { GWG above } \\
\text { guidelines }\end{array}$ & Statistic & $P$-value \\
\hline Perceived self-efficacy to manage GWG: score & 32.0 & $33.38(2.88)$ & $28.3(4.69)$ & $F=3.914$ & 0.036 \\
\hline Stress level: mean (SD) & 41.0 & $25.50(4.50)$ & $36.60(9.7 I)$ & $F=5.088$ & 0.016 \\
\hline $\begin{array}{l}\text { Patient-perceived physician patient- } \\
\text { centeredness in discussing GWG: mean (SD) }\end{array}$ & 2.07 & $2.51(.47)$ & $2.57(.50)$ & $F=.508$ & 0.609 \\
\hline $\begin{array}{l}\text { Readiness to adhere to GWG guidelines: } \mathrm{n}(\%) \\
\text { Not ready (I) } \\
\text { Ambivalent (2) } \\
\text { Ready (3) }\end{array}$ & $\begin{array}{l}0(0.0) \\
0(0.0) \\
I(100.0)\end{array}$ & $\begin{array}{l}0(0.0) \\
4(50.0) \\
4(50.0)\end{array}$ & $\begin{array}{l}\text { I (6.7) } \\
9(60.0) \\
5(33.3)\end{array}$ & $\chi^{2}=2.462$ & 0.652 \\
\hline
\end{tabular}

Notes: The ranges for the scores are outlined in the "Patient Characteristics" section. The range for perceived self-efficacy is I0-40. The range for stress level is 14-70. The range for patient-perceived patient centeredness is $\mathrm{I}-4$.

Abbreviation: GWG, gestational weight gain. 
the limitation in behavioral studies of not assessing fidelity and competency in the training in the intervention. ${ }^{59}$

\section{Limitations of the study}

There are a number of limitations in this study. First, this feasibility trial was underpowered to detect an effect, so firm conclusions cannot be drawn. Second, pertaining to this study, women received advise on GWG from their family physician at or just after 24 weeks' gestation. This is late in the second trimester and probably too late to have a significant impact on the amount of weight that they actually gain. Third, all the women attended practices in an urban region and could possibly have, based on their mean age and mean prepregnancy BMI, a higher SES. However, variables pertaining to SES were not collected.

\section{Conclusion}

This feasibility study required very little time commitment and entailed minimal disruption to the family physicians' practices. Nonetheless, it was very difficult to recruit family physicians for the study. Recent work based on Self-Efficacy Theory ${ }^{38}$ showed that prenatal care providers have very high perceived self-efficacy in discussing GWG with their patients under most circumstances, so perhaps it is not surprising that the intervention in the present study was unsuccessful in effecting any change at the patient level. However, most work in this area has demonstrated that prenatal care providers in fact do not engage in discussions about GWG with their patients, so there is clearly a mismatch in provider perceived self-efficacy and what actually transpires.

\section{Acknowledgment}

This work was supported by a grant from the Capital Health Research Fund for 2015-2017.

\section{Disclosure}

Dr Piccinini-Vallis has been a consultant for Novo Nordisk. Dr Vallis is a consultant and is on advisory boards for Novo Nordisk, Sanofi, and Valeant, and receives speaker's fees from Novo Nordisk, CSL Behring, Sanofi, Pfizer, Valeant, and Merck. The authors report no other conflicts of interest in this work.

\section{References}

1. Viswanathan M, Siega-Riz AM, Moos MK, et al. Outcomes of maternal weight gain. Evid Rep Technol Assess. 2008;168:1-223.

2. Cedergren MI. Optimal gestational weight gain for body mass index categories. Obstet Gynecol. 2007;110(4):759-764.
3. Chu SY, Callaghan WM, Bish CL, D'Angelo D. Gestational weight gain by body mass index among US women delivering live births, 2004-2005: fueling future obesity. Am J Obstet Gynecol. 2009;200(3): 271.e1-e7.

4. Piccinini-Vallis H, Lee-Baggley DL, Stewart M, Ryan BL. Gestational weight gain trajectories in Nova Scotia primary care. Can Family Physician. 2016;62:407-414.

5. Nova Scotia Atlee Perinatal Database Report of Indicators 2005-2014; 2015. Available from: http://rcp.nshealth.ca/sites/default/files/publications/nsapd_indicator_report_2005_2014.pdf. Accessed September 21, 2018.

6. Institute of Medicine. Weight Gain During Pregnancy: Reexamining the Guidelines. Washington, DC: National Academies Press; 2009.

7. Rasmussen KM, Catalano PM, Yaktine AL. New guidelines for weight gain during pregnancy: what obstetrician/gynecologists should know. Curr Opin Obstet Gynecol. 2009;21(6):521-526.

8. Davies GAL, Maxwell C, Mcleod L, et al. Obesity in pregnancy. Int $J$ Gynecol Obstet. 2010;110(2):167-173.

9. McDonald SD, Pullenayegum E, Bracken K, et al. Comparison of midwifery, family medicine, and obstetric patients' understanding of weight gain during pregnancy: a minority of women report correct counselling. J Obstet Gynaecol Can. 2012;34(2):129-135.

10. Shub A, Huning EY, Campbell KJ, Mccarthy EA. Pregnant women's knowledge of weight, weight gain, complications of obesity and weight management strategies in pregnancy. BMC Res Notes. 2013;6:278.

11. Tovar A, Guthrie LB, Platek D, Stuebe A, Herring SJ, Oken E. Modifiable predictors associated with having a gestational weight gain goal. Matern Child Health J. 2011;15(7):1119-1126.

12. Headen IE, Davis EM, Mujahid MS, Abrams B. Racial-ethnic differences in pregnancy-related weight. Adv Nutr. 2012;3(1):83-94.

13. Stotland NE, Haas JS, Brawarsky P, Jackson RA, Fuentes-Afflick E, Escobar GJ. Body mass index, provider advice, and target gestational weight gain. Obstet Gynecol. 2005;105(3):633-638.

14. Phelan S, Phipps MG, Abrams B, Darroch F, Schaffner A, Wing RR. Practitioner advice and gestational weight gain. J Womens Health. 2011; 20(4):585-591.

15. Cogswell ME, Scanlon KS, Fein SB, Schieve LA. Medically advised, mother's personal target, and actual weight gain during pregnancy. Obstet Gynecol. 1999;94(4):616-622.

16. Jeffries K, Shub A, Walker SP, Hiscock R, Permezel M. Reducing excessive weight gain in pregnancy: a randomised controlled trial. Med J Aust. 2009;191(8):429-433.

17. Ferrari RM, Siega-Riz AM. Provider advice about pregnancy weight gain and adequacy of weight gain. Matern Child Health J. 2013;17(2): 256-264.

18. Butler C, Rollnick S, Stott N. The practitioner, the patient and resistance to change: recent ideas on compliance. CMAJ. 1996;154(9):1357-1362.

19. Little P, Everitt H, Williamson I, et al. Observational study of effect of patient centredness and positive approach on outcomes of general practice consultations. Br Med J. 2001;323(7318):908-911.

20. Saha S, Beach MC. The impact of patient-centered communication on patients' decision making and evaluations of physicians: a randomized study using video vignettes. Patient Educ Couns. 2011;84(3):386-392.

21. Butler CC, Simpson SA, Hood K, et al. Training practitioners to deliver opportunistic multiple behaviour change counselling in primary care: a cluster randomised trial. Br Med J. 2013;346:f1 191.

22. Stewart MB, Weston JB, McWhinney W, McWilliam CL, Freeman T. Patient-Centered Medicine: Transforming the Clinical Method.2nd ed. Abingdon: Radcliffe Health; 2003.

23. Vallis M, Piccinini-Vallis H, Sharma AM, Freedhoff Y. Clinical review: modified 5 As: minimal intervention for obesity counseling in primary care. Can Fam Physician. 2013;59(1):27-31.

24. Epstein RM, Franks P, Shields CG, et al. Patient-centered communication and diagnostic testing. Ann Fam Med. 2005;3(5):415-421.

25. Stewart M, Ryan BL, Bodea C. Is patient-centred care associated with lower diagnostic costs? Healthc Policy. 2011;6(4):27-31.

26. Bertakis KD, Azari R. Patient-centered care is associated with decreased health care utilization. J Am Board Fam Med. 2011;24(3):229-239. 
27. Zolnierek KB, Dimatteo MR. Physician communication and patient adherence to treatment: a meta-analysis. Med Care. 2009;47(8): 826-834.

28. Brown JB, Stewart M, Ryan BL. Assessing Communication Between Patients and Physicians: The Measure of Patient-Centered Communication (MPCC). Working Paper Series \#95-2. London, Ontario: Center for Studies in Family Medicine; 2001.

29. Stewart MML, Ryan BL, Brown JB. The Patient Perception of PatientCenteredness Questionnaire (PPPC). Working Paper Series \#04-1. London, Ontario: Center for Studies in Family Medicine; 2004.

30. Stewart M, Brown JB, Donner A, et al. The impact of patient-centered care on outcomes. J Fam Pract. 2000;49(9):796-804.

31. Clayton MF, Latimer S, Dunn TW, Haas L. Assessing patient-centered communication in a family practice setting: how do we measure it, and whose opinion matters? Patient Educ Couns. 2011;84(3):294-302.

32. Potter MB, Vu JD, Croughan-Minihane M. Weight management: what patients want from their primary care physicians. J Fam Pract. 2001;50(6):513-518

33. Piccinini-Vallis H. Diagnosis and management of obesity: A survey of general practitioners' awareness of and familiarity with the 2006 Canadian Clinical Practice Guidelines. Can J Diabetes. 2011;35(3): 269-273.

34. Booth AO, Nowson CA. Patient recall of receiving lifestyle advice for overweight and hypertension from their General Practitioner. BMC Fam Pract. 2010;11:8.

35. Epstein L, Ogden J. A qualitative study of GPs' views of treating obesity. Br J Gen Pract. 2005;55(519):750-754.

36. Alexander SC, Ostbye T, Pollak KI, Gradison M, Bastian LA, Brouwer RJ. Physicians' beliefs about discussing obesity: results from focus groups Am J Health Promot. 2007;21(6):498-500.

37. Leverence RR, Williams RL, Sussman A, Crabtree BF, Clinicians RN, RIOS Net Clinicians. Obesity counseling and guidelines in primary care: a qualitative study. Am J Prev Med. 2007;32(4):334-339.

38. Piccinini-Vallis H. Clinician self-efficacy in initiating discussions about gestational weight gain. Can Fam Physician. 2017;63(7):e341-e349.

39. Rubak S, Sandbaek A, Lauritzen T, Borch-Johnsen K, Christensen B. General practitioners trained in motivational interviewing can positively affect the attitude to behaviour change in people with type 2 diabetes. One year follow-up of an RCT, ADDITION Denmark. Scand J Prim Health Care. 2009;27(3):172-179.

40. Sargeant J, Valli M, Ferrier S, Macleod H. Lifestyle counseling in primary care: opportunities and challenges for changing practice. Med Teach. 2008;30(2):185-191.

41. Madson MB, Loignon AC, Lane C. Training in motivational interviewing: a systematic review. J Subst Abuse Treat. 2009;36(1):101-109.

42. Chossis I, Lane C, Gache P, et al. Effect of training on primary care residents' performance in brief alcohol intervention: a randomized controlled trial. J Gen Intern Med. 2007;22(8):1144-1149.

43. Pollak KI, Alexander SC, Coffman CJ, et al. Physician communication techniques and weight loss in adults: Project CHAT. Am J Prev Med. 2010;39(4):321-328.

44. Heslehurst N, Crowe L, Robalino S, Sniehotta FF, Mccoll E, Rankin J. Interventions to change maternity healthcare professionals' behaviours to promote weight-related support for obese pregnant women: a systematic review. Implement Sci. 2014;9(1):97.
45. Carroll JK, Antognoli E, Flocke SA. Evaluation of physical activity counseling in primary care using direct observation of the 5As. Ann Fam Med. 2011;9(5):416-422.

46. Abidi S, Vallis M, Raza Abidi SS, Piccinini-Vallis H, Imran SA. D-WISE: Diabetes Web-Centric Information and Support Environment: conceptual specification and proposed evaluation. Can J Diabetes. 2014;38(3):205-211.

47. Whitlock EP, Orleans CT, Pender N, Allan J. Evaluating primary care behavioral counseling interventions: an evidence-based approach. Am J Prev Med. 2002;22(4):267-284.

48. Rueda-Clausen CF, Benterud E, Bond T, Olszowka R, Vallis MT, Sharma AM. Effect of implementing the 5As of obesity management framework on provider-patient interactions in primary care. Clin Obes. 2014;4(1):39-44.

49. Canadian Obesity Network. 5As of Health Pregnancy Weight Gain; 2014. Available from: https://obesitycanada.ca/5as-pregnancy/. Accessed October 5, 2018.

50. Harvey BJ, Lang ES, Frank JR. The Research Guide: A Primer for Residents, Other Health Care Trainees, and Practitioners. Ottawa: Royal College of Physicians and Surgeons of Canada; 2011.

51. Asch S, Connor SE, Hamilton EG, Fox SA. Problems in recruiting community-based physicians for health services research. J Gen Intern Med. 2000;15(8):591-599.

52. Johnston S, Liddy C, Hogg W, Donskov M, Russell G, Gyorfi-Dyke E. Barriers and facilitators to recruitment of physicians and practices for primary care health services research at one centre. BMC Med Res Methodol. 2010;10:109.

53. Vallis M, Lee-Baggley D, Sampalli T, et al. Equipping providers with principles, knowledge and skills to successfully integrate behaviour change counselling into practice: a primary healthcare framework. Public Health. 2018;154:70-78.

54. Holland E, Moore Simas TA, Doyle Curiale DK, Liao X, Waring ME. Self-reported pre-pregnancy weight versus weight measured at first prenatal visit: effects on categorization of pre-pregnancy body mass index. Matern Child Health J. 2013;17(10):1872-1878.

55. Vaglio JC, Conard MW, Poston WSC, O’Keefe JH, Spertus JA. Testing the performance of an abbreviated social support questionnaire in cardiac patients. Am Heart J. 2002;144(5):896.

56. Cohen S, Kamarck T, Mermelstein R. A global measure of perceived stress. J Health Soc Behav. 1983;24(4):385-396.

57. Schwarzer R, Jerusalem M. Generalized Self-Efficacy scale. In: Weinman J, Wright S, Johnston M, editors. Measures in Health Psychology: A User's Portfolio. Causal and Control Beliefs. Windsor, UK: NFER-NELSON; 1995:35-37.

58. Vallis M. Behaviour change counselling - how do I know if I am doing it well? The development of the Behaviour Change Counselling Scale (BCCS). Can J Diabetes. 2013;37(1):18-26.

59. Campbell TS, Bacon SL, Corace K, Lavoie KL, Rash JA, Vallis M. Comment on Pladevall et al, "A Randomized Controlled Trial to Provide Adherence Information and Motivational Interviewing to Improve Diabetes and Lipid Control". Diabetes Educ. 2015;41(5):625-626.
International Journal of Women's Health

\section{Publish your work in this journal}

The International Journal of Women's Health is an international, peerreviewed open-access journal publishing original research, reports, editorials, reviews and commentaries on all aspects of women's healthcare including gynecology, obstetrics, and breast cancer. The manuscript management system is completely online and includes

\section{Dovepress}

a very quick and fair peer-review system, which is all easy to use. Visit http://www.dovepress.com/testimonials.php to read real quotes from published authors. 